\title{
COEXISTENCE OF THREE SPECIALIST APHIDS ON COMMON MILKWEED, ASCLEPIAS SYRIACA
}

\author{
R. A. Smith, ${ }^{1}$ K. A. Mooney, ${ }^{1,2}$ and A. A. Agrawal ${ }^{1,3}$ \\ ${ }^{1}$ Department of Ecology and Evolutionary Biology, Corson Hall, Cornell University, Ithaca, New York 14853 \\ ${ }^{2}$ Department of Ecology and Evolutionary Biology, Steinhaus Hall, University of California, Irvine, California 92697 USA
}

Abstract. Coexistence of host-specific herbivores on plants is believed to be governed by interspecific interactions, but few empirical studies have systematically unraveled these dynamics. We investigated the role of several factors in promoting coexistence among the aphids Aphis nerii, Aphis asclepiadis, and Myzocallis asclepiadis that all specialize on common milkweed (Asclepias syriaca). Competitive exclusion is thought to occur when interspecific competition is stronger than intraspecific competition. Consequently, we investigated whether predators, mutualists, or resource quality affected the strength of intra- vs. interspecific competition among aphids in factorial manipulations of competition with exposure to predation, ants, and variable plant genotypes in three separate experiments. In the predation $\times$ competition experiment, predators reduced aphid per capita growth by $66 \%$, but the strength of intra- and interspecific competition did not depend on predators. In the ants $\times$ competition experiment, ants reduced per capita growth of $A$. nerii and M. asclepiadis (neither of which were mutualists with ants) by approximately one-half. In so doing, ants ameliorated the negative effects of these competitors on ant-tended A. asclepiadis by two-thirds, representing a novel benefit of ant-aphid mutualism. Nevertheless, ants alone did not explain the persistence of competitively inferior $A$. asclepiadis as, even in the presence of ants, interspecific competition remained stronger than intraspecific competition. In the plant genotype $\times$ competition experiment, both $A$. asclepiadis and $M$. asclepiadis were competitively inferior to $A$. nerii, with the strength of interspecific competition exceeding that of intraspecific competition by $83 \%$ and $23 \%$, respectively. Yet these effects differed among milkweed genotypes, and there were one or more plant genotypes for each aphid species where coexistence was predicted.

A synthesis of our results shows that predators play little or no role in preferentially suppressing competitively dominant $A$. nerii. Nonetheless, $A$. asclepiadis benefits from ants, and $A$. asclepiadis and $M$. asclepiadis may escape competitive exclusion by $A$. nerii on select milkweed genotypes. Taken as a whole, the coexistence of three host-specific aphid species sharing the same resource was promoted by the dual action of ants as antagonists and mutualists and by genetic diversity in the plant population itself.

Key words: ant-aphid mutualism; Aphis asclepiadis; Aphis nerii; common milkweed; competition; Myzocallis asclepiadis; plant genetic variation; plant-insect interactions; predator exclusion.

\section{INTRODUCTION}

Classical ecological theory predicts that interspecific competition plays a dominant role in structuring biological communities (Hutchinson 1978, Schoener 1983). Of course, the universal importance of competition has been called into question. For example, Hairston et al.'s seminal paper in 1960 asserted that herbivores must not be resource limited because the world is green (i.e., most plants are not completely defoliated). Hairston et al. (1960) concluded that predators and parasitoids must limit the abundance of herbivores to levels low enough to preclude interspecific competition. This paper influenced decades of research, much of which was based on classical competition

Manuscript received 4 September 2007; revised 29 November 2007; accepted 4 December 2007. Corresponding Editor: W. E. Snyder.

${ }^{3}$ Corresponding author. E-mail: aa337@cornell.edu theory and sought to demonstrate examples of competition between herbivores through direct and indirect evidence such as resource partitioning (McClure and Price 1975, Rathcke 1976, Addicot 1978, Strong 1982, Strong et al. 1984, Edson 1985, Denno et al. 1995, Kaplan and Denno 2007).

The current synthesis in ecology is that numerous factors can structure herbivore communities (Karban 1989, Hunter and Price 1992), including plant structure and quality (Farnsworth et al. 2002, Johnson and Agrawal 2005), predators and parasitoids (Halaj and Wise 2001, Chase et al. 2002, Bonsall et al. 2005, Mooney 2007), mutualistic interactions (Bronstein 1994, Wimp and Whitham 2001, Mooney 2006), metapopulation dynamics (Harrison et al. 1995, Valone and Brown 1995, Bonsall et al. 2005), feeding and foraging efficiencies (Kohler 1992, Chase et al. 2001, Farnsworth et al. 2002), and interspecific competition (Denno et al. 1995, Kaplan and Denno 2007). There has been a long 
and vigorous debate over the importance of these ecological factors, especially the importance of interspecific competition for herbivorous insects. Lawton and Strong (1981) concluded that interspecific competition is too rare or too weak to be a significant factor in structuring insect herbivore communities. However, Denno et al. (1995) reviewed the literature and reported that interspecific competition was an important and common factor for herbivores. Furthermore, they found that interspecific competition was most likely to occur when the species involved were closely related, nonnative, sessile, aggregative, and were feeding on discrete resources or were feeding on grasses or forbs. Since this review, many additional studies have been conducted that largely support the notion that competition can be important for herbivores, yet few have addressed the importance of ecological factors in modulating the strength of competition (Kaplan and Denno 2007).

Coexistence between species that share the same resource may be favored if the outcome of competition changes (i.e., trades off) based on ecological context. For example, one species may be competitively dominant to another in the presence of predators, but competitively subordinate in their absence. Where the level of predation is heterogeneous, this interaction between predation and competition may favor coexistence (Paine 1966, Gurevitch et al. 2000, Chase et al. 2002). Remarkably, very few studies have simultaneously examined the impacts of multiple factors on the strength of competition. Here we investigate competition and the factors promoting coexistence among three aphid species that feed sympatrically on common milkweed, Asclepias syriaca (L.). Of the herbivores feeding on milkweed, the three aphids seem the most likely to compete. These species fit into five of the six categories that Denno et al. (1995) conclude are reliable predictors of competition: they are closely related (two are congeners, all are in the family Aphididae), sessile, aggregative, feed on an herbaceous plant, and all feed on the same discrete resource of that same host species (milkweed phloem sap).

Despite the fact that competition is predicted to be strong, these species frequently co-occur on plants in the field and the factors mediating their coexistence remain unknown. While recent theory has proposed that coexistence does not require trade-offs (Hubbell 2001), this work is based on the assumption of species being equivalent in their demography and competitive abilities. Past work on the three milkweed aphid species has shown them to be decidedly distinct in their demographic parameters and that competition among these species is likely to be strongly asymmetrical (Mooney et al. 2008).

We investigated whether competitive superiority among these aphids trades off based on the presence of predators, ants (which are mutualists with some but not all aphids), and genetically based variation in host plant quality. Despite the rising interest in the latter two factors, few, if any, studies have examined their role in coexistence (Booth and Grime 2003, Schmitt and Holbrook 2003, Whitham et al. 2003, Umbanhowar and McCann 2005). Competitive exclusion is thought to occur when interspecific competition is stronger than intraspecific competition, i.e., a species must compete more strongly with conspecifics than with other community members or it will be driven to local extinction (Tilman 1982, Chesson 2000, Ricklefs and Miller 2000). Consequently, we tested whether these factors (predation, ants, plant genotype) affected the relative strength of intra- and interspecific competition among the three aphids. As such, our factorial manipulations of how ecological factors modulate the potential for coexistence are unique in their comprehensiveness.

\section{Methods}

\section{Natural history}

Comprising only 12 species, the herbivorous insect community of common milkweed Asclepias syriaca (hereafter referred to as milkweed) spans four orders: Lepidoptera, Coleoptera, Diptera, and Hemiptera (Agrawal and Malcolm 2002, Agrawal 2005). In eastern North America, milkweed is a native perennial forb that grows in old fields. We focus here on the three specialist aphids (Hemiptera: Aphididae) that feed sympatrically on milkweed: Aphis asclepiadis (Fitch), Aphis nerii (Boyer de Fonscolome), and Myzocallis asclepiadis (Monel). Aphis asclepiadis and A. nerii feed gregariously and preferentially on apical leaves, while $M$. asclepiadis feeds in a dispersed pattern, typically on the undersides of lower leaves. While A. asclepiadis is nearly always tended by ants, $A$. nerii is only occasionally tended, while $M$. asclepiadis is untended. Aphis nerii is aposematic (bright yellow and chemically defended) while $M$. asclepiadis and $A$. asclepiadis are relatively inconspicuous (clear, green or brown, respectively). While the two Aphis species are phenotypically plastic and produce both winged and unwinged morphs, adults of $M$. asclepiadis are always winged.

\section{Experimental plants and aphid colonies}

We grew milkweed plants in a similar manner for aphid colonies and for the experiments that used laboratory plants. We germinated seeds collected in Tompkins County, New York, USA, and planted them in $500-\mathrm{mL}$ pots with potting soil and grew them in growth chambers $\left(25^{\circ} \mathrm{C}: 22^{\circ} \mathrm{C}\right.$ on a $14 \mathrm{~L}: 10 \mathrm{D}$ cycle $)$, fertilizing the plants weekly and watering them as needed. We founded our aphid colonies from single individuals of each aphid species collected from $A$. syriaca in Tompkins County and maintained small populations by serial transfer on potted $A$. syriaca in a growth chamber under the conditions described.

\section{Experimental approach}

In each of three experiments we factorially manipulated aphid competition with a second ecological factor, 
either presence of arthropod predators, presence of ants, or genetically based variation in host plant quality. The aphid competition treatments included each species alone, and all three aphids together. The sample size required to include pairwise competition treatments was logistically prohibitive. In the multispecies treatment, the density of each aphid species was one-third of that in the single-species treatments, thus keeping initial aphid density constant among the four treatment levels. With this substitutive design, the competition treatment tests for differences between intra- and interspecific competition. To facilitate analysis and interpretation (see Methods: Statistical methods), we assessed the impact of competition and the second ecological factor in separate analyses for each aphid species. In addition, this sort of design allows for an interpretation of the impact of herbivore species richness on abundance and multitrophic interactions (e.g., Duffy et al. 2007).

Our use of a substitutive design and focus on inter- vs. intraspecific competition is critical to coexistence theory. Long-standing models have predicted that a species can only persist in a community if intraspecific competition is stronger than interspecific competition (Tilman 1982, Chesson 2000, Ricklefs and Miller 2000). A significant interaction between competition and the second ecological factor (predation, ants, or plant quality) on the focal aphid species would indicate that the relative strength of intra- and interspecific competition depends on this second factor. If competitive superiority among the aphid species trades off based on a second ecological factor, natural variation in that factor is predicted to promote coexistence.

\section{Predation $\times$ competition}

In this experiment we investigated whether predators altered the relative strength of intra- and interspecific competition for each aphid species. We worked in a natural population of milkweed in Tompkins County in the months of July and August 2006. There were two predator treatments (with and without predators) and, as described (see Methods: Experimental approach), four aphid treatments (each aphid alone and all three together) with 12 replicates per factorial combination for a total of 96 plants.

We cleared all plants of arthropods by hand and enclosed each plant in a spun polyester bag sealed to the plant stem such that a minimum of 12 fully expanded leaves were enclosed. We selected only nonflowering plants of $\sim 1.0 \mathrm{~m}$ in height. After placing 12 aphids on each plant (12 and 4 aphids per species in single- and mixed-species treatments, respectively), we allowed the aphid colonies to grow within the enclosures. We chose these densities because typically only one or a few aphids colonize each plant in the beginning of the season, and rapid population growth typically results thereafter. After 12 days, we implemented the predator treatment by cutting three vertical slits in one-half of the bags to allow predator access. We counted the number of aphids and the number of predators immediately before implementing the predator treatment (day 12) and subsequently on days 15,23 , and 42 . All data for this and subsequent experiments, are reported in terms of per capita progeny production (final aphid density divided by initial aphid density per plant).

\section{Ants $\times$ competition}

In this experiment, we investigated whether ants (as predators and mutualists) altered the relative strength of inter- and intraspecific competition for each aphid species. We conducted this experiment in an old field in Tompkins County in the months of July and August 2006, $\sim 2 \mathrm{~km}$ from the site used in the predation $\times$ competition experiment. There were two ant treatments (exclusion and control) and, as described (see Methods: Experimental approach), four aphid treatments (each aphid alone and all three together) with 10 replicates per factorial combination for a total of 80 plants.

We grew plants in growth chambers (see Methods: Experimental plants and aphid colonies) and out-planted them at an average height of $15 \mathrm{~cm}$. We arranged 16 plants in 2.4-m radius circles around five active mounds of the ant Formica podzolica (Francour) and randomly assigned two plants each to one of the eight treatments. We excluded ants by sinking aluminum rings (radius, $12.5 \mathrm{~cm}$; height, $20 \mathrm{~cm}$ ) into the ground around each plant and coating the outside surface with a sticky paste (Tanglefoot Company, Grand Rapids, Michigan, USA). On control plants, we set slightly shorter rings $(15 \mathrm{~cm}$ height) loosely on the ground without sticky paste. These rings did not exclude ants but controlled for artifacts from the physical presence of the ring. After placing 15 aphids on each plant (15 and 5 aphids per species in single- and mixed-species treatments, respectively), we counted aphids, ants, and predators after 11, 16,22 , and 30 days. In addition, because ant numbers were usually quite low and variable, we counted ants alone on days $26,28,29,30$, and 33 to gain precision in our estimates of ant visitation.

To characterize the ecological relationships between ants and the three species of aphids, we took quantitative observations of the behavior of ants on individual experimental plants. We recorded the time spent by a haphazardly selected ant in each of four specific behaviors: predation, roaming, aphid tending, and harvesting honeydew from leaf surfaces without aphids. We watched each ant for five minutes or until it left the plant. We took a minimum of seven observations of ants on plants hosting each aphid species alone.

\section{Plant genotype $\times$ competition}

In this experiment, we investigated whether genetically based variation in milkweed traits altered the relative strength of intra- and interspecific competition for each aphid species. In a growth chamber set to the conditions described (see Methods: Experimental plants and aphid colonies), we replicated the four competition treatments 
(each aphid alone and all three together; see Methods: Experimental approach) on each of 11 full-sibling milkweed genetic families. With four replicates per factorial combination, the total sample size was 176 plants. Seeds from a single fruit of $A$. syriaca are full siblings because of the pollinia pollination system of milkweed, i.e., a single pollen sac or pollinium sires all of the seeds from a flower (Gold and Shore 1995). The 11 genetic families were collected from a single plant population at the same field where the ants $x$ competition experiment was conducted.

When the experimental plants had reached an average height of $8 \mathrm{~cm}$, we placed six aphids on each plant $(6$ and 2 aphids per species in single and mixed-species treatments, respectively). We counted aphids once on each plant between seven and 10 days after inoculation. Additionally, we measured four plant traits (latex exudation, specific leaf area, trichomes per unit area, and cardenolide concentration). Although all of these traits varied significantly among plant genotypes (R. A. Smith, K. A. Mooney, and A. A. Agrawal, unpublished data), none were positively or negatively correlated with aphid success and these data are not reported here.

\section{Statistical methods}

In our experimental design, the effect of intra- vs. interspecific competition for each aphid is assessed by comparing aphid performance when it occurs alone (intraspecific competition) vs. when it occurs with heterospecifics (interspecific competition). In each experiment, counts of the three aphid species in the mixedspecies treatment were taken from the same set of plants. Consequently, these data are not independent of each other. The optimal response to this problem (to have three separate sets of plants for the mixed-species treatment) would have increased our sample size by one-half and was not logistically feasible. Instead, we performed separate analyses for each aphid species. In this way, there were no issues of data independence within each individual analysis (i.e., in the mixed treatment, aphids of each species were only analyzed once), although the separate analyses for each aphid species have some interdependence.

In the separate analyses for each aphid species, we tested for the main effects and interactions between competition (intra- vs. interspecific competition) and the second ecological factor (predation, ants, or host plant quality). Where there were significant interactions between competition and the second ecological factor, we characterized the nature of the interaction by performing separate tests for competition effects across each level of the second factor.

In the predation $\times$ competition and ants $\times$ competition experiments, we averaged counts across time because aphid counts were low at some time points; averaging across time reduced the number of observations with few or no aphids and thus improved the distribution of the data with respect to the assumptions of the statistical analyses we employed. Additionally, in exploratory analyses we observed that the interactions between time and other factors were uncommon. Where they occurred they were due to differences in the magnitude, not the direction, of effects changing over time. For completeness, the time courses of our results from these two experiments are presented in Appendix A.

All analyses were conducted using SAS 9.1 (SAS Institute 2003). In all three experiments, the data were not normally distributed. For the predation $\times$ competition and ants $\times$ competition experiments we used PROC GENMOD, fitting our data to a Poisson distribution using the PSCALE option to account for overdispersion (Allison and SAS Institute 1999). In the ants $\times$ competition experiment we included ant mound as a blocking factor in the model. For the plant genotype $\times$ competition experiment, milkweed family was a random effect. Because PROC GENMOD (and similar procedures using generalized linear models) cannot test for the significance of random effects, we log-transformed the data to meet assumptions of normality and used PROC MIXED. We tested for the effects of milkweed family and interactions between competition and family with log likelihood ratio tests (Littell 2006).

For the behavioral observations, we performed separate tests for the effect of aphid species on the percentages of time ants spent at each behavior (tending, foraging, and other behaviors) by ANOVA using PROC GLM. To assess the effectiveness of our predator exclusion treatment, we compared predator abundance by ANOVA using PROC GLM. For this analysis, we used data from the single sampling date for each plant on which the maximum predator abundance was observed to avoid repeated counts of the same predators. In the ants $\times$ competition experiment, we also compared predator abundance in treatments with and without ants. Here we encountered relatively few predators in our surveys. Consequently, we used a chisquare test to examine effects of ant exclusion on predators by comparing the number of plants in ant exclusion and control treatments on which predators were observed at least once.

\section{Results \\ Predation $\times$ competition}

The number of predators observed on control plants was 75-fold higher than on predator-exclusion plants (mean $\pm \mathrm{SE}, 1.5 \pm 0.49$ on controls, and $0.02 \pm 0.003$ on exclusion plants, $F_{1,94}=31.04, P<0.0001$ ), and the predator community was dominated by coccinellid larvae, syrphid larvae, salticid spiders, and pentatomids. Exposure of aphid colonies to predation reduced the populations of $A$. asclepiadis, $A$. nerii, and $M$. asclepiadis by an average of $66 \%$ (Table 1, Fig. 1a-c). For each aphid species, there were main effects of predation, but neither competition nor competition $\times$ predation interactions $(P>0.05$ in latter cases $)$. 
TABLE 1. Statistical results for factorial experiments crossing competition (intra- vs. interspecific) with predation, ants, or host plant genotype.

\begin{tabular}{|c|c|c|c|c|c|c|}
\hline \multirow[b]{2}{*}{ Factor(s) } & \multicolumn{2}{|c|}{ A. asclepiadis } & \multicolumn{2}{|c|}{ A. nerii } & \multicolumn{2}{|c|}{ M. asclepiadis } \\
\hline & $F$ & $P$ & $F$ & $P$ & $F$ & $P$ \\
\hline \multicolumn{7}{|l|}{ Competition and predation $\dagger$} \\
\hline Competition & 0.59 & 0.45 & 0.12 & 0.73 & 0.11 & 0.74 \\
\hline Predation & 5.06 & 0.03 & 19.28 & $<\mathbf{0 . 0 1}$ & 23.64 & $<\mathbf{0 . 0 1}$ \\
\hline Competition $\times$ predation & 0.35 & 0.56 & 0.27 & 0.61 & 1.59 & 0.21 \\
\hline \multicolumn{7}{|l|}{ Competition and ants } \\
\hline Competition & 21.52 & $<\mathbf{0 . 0 1}$ & 0.90 & 0.35 & 6.20 & 0.02 \\
\hline Ants & 9.41 & $<\mathbf{0 . 0 1}$ & 4.98 & 0.03 & 13.02 & $<\mathbf{0 . 0 1}$ \\
\hline Competition $\times$ ants & 3.89 & 0.06 & 0.01 & 0.93 & 0.01 & 0.92 \\
\hline Ant mound & 22.66 & $<\mathbf{0 . 0 1}$ & 3.54 & 0.03 & 1.49 & 0.23 \\
\hline \multicolumn{7}{|c|}{ Competition and plant genotype } \\
\hline Competition & 38.84 & $<\mathbf{0 . 0 1}$ & 37.65 & $<\mathbf{0 . 0 1}$ & 7.83 & 0.01 \\
\hline Date of aphid count & 2.65 & 0.08 & 7.08 & $<\mathbf{0 . 0 1}$ & 3.53 & 0.04 \\
\hline Genotype & 0.2 & 0.65 & 4.2 & 0.04 & 0 & 1.0 \\
\hline Competition $\times$ genotype & 9 & $<\mathbf{0 . 0 1}$ & 4.2 & 0.04 & 6 & 0.01 \\
\hline
\end{tabular}

Notes: The aphid genera are Aphis and Myzocallis. Significant results $(P<0.05)$ are shown in boldface; results were considered marginally significant at $P<0.10$.

$\dagger$ For all tests, $\mathrm{df}=1,43$.

$\$$ For all tests, $\mathrm{df}=1,32$, except for ant mound $(\mathrm{df}=4,32)$.

$\S$ For $F$ tests of competition, $\mathrm{df}=1,20$; for date, $\mathrm{df}=1,60$.

The test statistic is $\chi^{2}$ from log-likelihood ratio test rather than $F ; \mathrm{df}=1$.

\section{Ants $\times$ competition}

The main effect of competition (intra- vs. interspecific) differed significantly for $M$. asclepiadis and A. asclepiadis but not for $A$. nerii. Compared to intraspecific competition, interspecific competition increased the abundance of $M$. asclepiadis by $75 \%$ and decreased the abundance of $A$. asclepiadis by $53 \%$ (Table 1, Fig. 1d-f).

The main effect of ants was significant for all species, but again the effects were species specific. Ants decreased the abundance of $M$. asclepiadis and A. nerii by $51 \%$ and $53 \%$, respectively (Fig. 1e, f), but increased the abundance of $A$. asclepiadis by $26 \%$ (Fig. 1d; Table 1). Only for $A$. asclepiadis was there a suggestion of an ants $\times$ competition interaction $(P=0.0574)$; interspecific competition decreased the abundance of $A$. asclepiadis both when ants were present $\left(F_{1,14}=15.58, P<0.0001\right)$ and absent $\left(F_{1,14}=5.44, P=0.0196\right)$, but ants ameliorated the negative affects of interspecific competition by two-thirds. As a consequence, ants provided a detectable benefit to $A$. asclepiadis in the presence of competitors $\left(F_{1,14}=8.13, P=0.0044\right)$ but not in their absence $\left(F_{1,14}=1.92, P=0.17\right.$; Fig. $\left.1 d\right)$. In total we observed only 23 predators on plants in this experiment. Predators occurred one or more times on three of the 40 ant exclusion plants $(7.5 \%)$ and 10 of the 40 control plants $(25 \%)$, a difference that was marginally significant $\left(\chi^{2}=3.77, \mathrm{df}=1, P=0.0522\right)$. Thus, ants provided no benefit to $A$. asclepiadis in the absence of competitors even while reducing the predator frequency by threefourths.

Our behavioral observations suggested that ants on plants with $A$. asclepiadis or A. nerii spent the majority of their time tending aphids, but ants spent a greater percentage of time tending when on plants with $A$. asclepiadis than when on plants with $A$. nerii (Table 2). On plants with $M$. asclepiadis, ants spent most of their time harvesting honeydew on leaves beneath aphid colonies. Ants spent the same amount of time roaming no matter what species of aphid was present (Table 2). We did not observe any predation of aphids by ants.

\section{Plant genotype $\times$ competition}

Compared to intraspecific competition, interspecific competition overall negatively impacted $A$. asclepiadis by $83 \%$ and $M$. asclepiadis by $23 \%$, but benefited $A$. nerii by $229 \%$ (Table 1, Fig. 1g-i). For all three aphids, the relative strength of intra- and interspecific competition differed among the 11 milkweed genotypes (competition $\times$ milkweed family interaction; Table 1$)$. When in the presence of conspecifics, abundances of $A$. asclepiadis, A. nerii, and M. asclepiadis varied 13.6-fold, 2.7-fold, and 1.5-fold, respectively, among the 11 milkweed families. In the presence of heterospecifics, aphid abundances of $A$. asclepiadis, A. nerii, and M. asclepiadis varied 5.5-fold, 2.4-fold, and 2.7-fold, respectively, among the 11 milkweed families. Tests for the effect of competition for each species on each family showed that for every aphid species there were several families in which interspecific competition did not differ from intraspecific competition (Appendix B). For A. asclepiadis, seven of the 11 families showed a significant difference between intra- and interspecific competition, and for one of these families the trend (i.e., line slope, Fig. 1g) was for a weaker effect of interspecific competition. For $M$. asclepiadis, nine families did not show significant differences between intra- and interspecific competition, while two families showed significant or marginally significant differences. For these two 


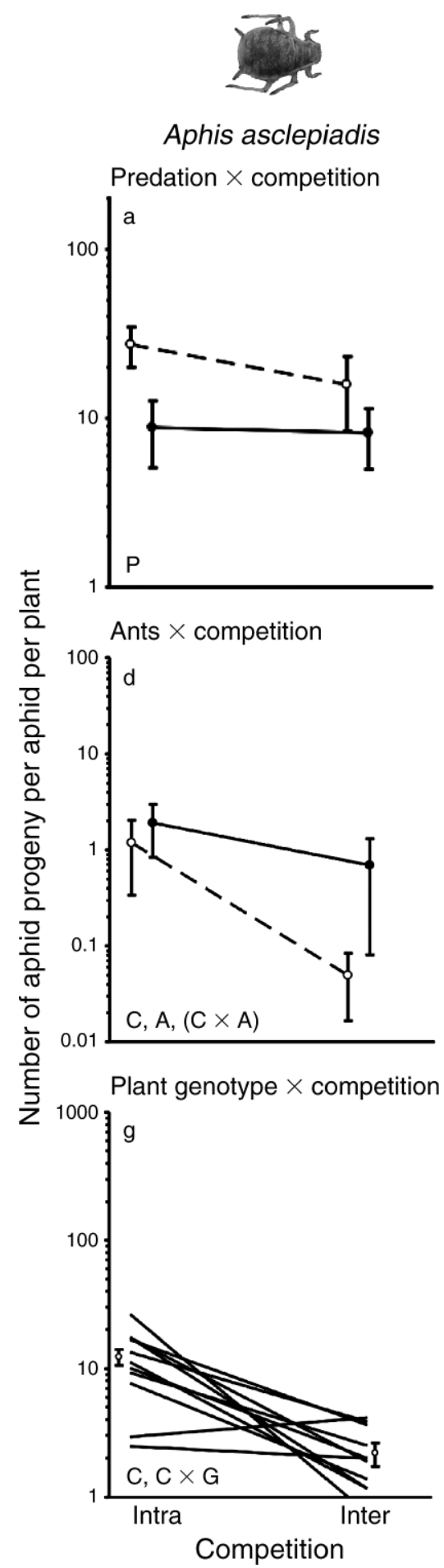

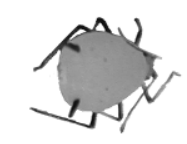

Aphis nerii
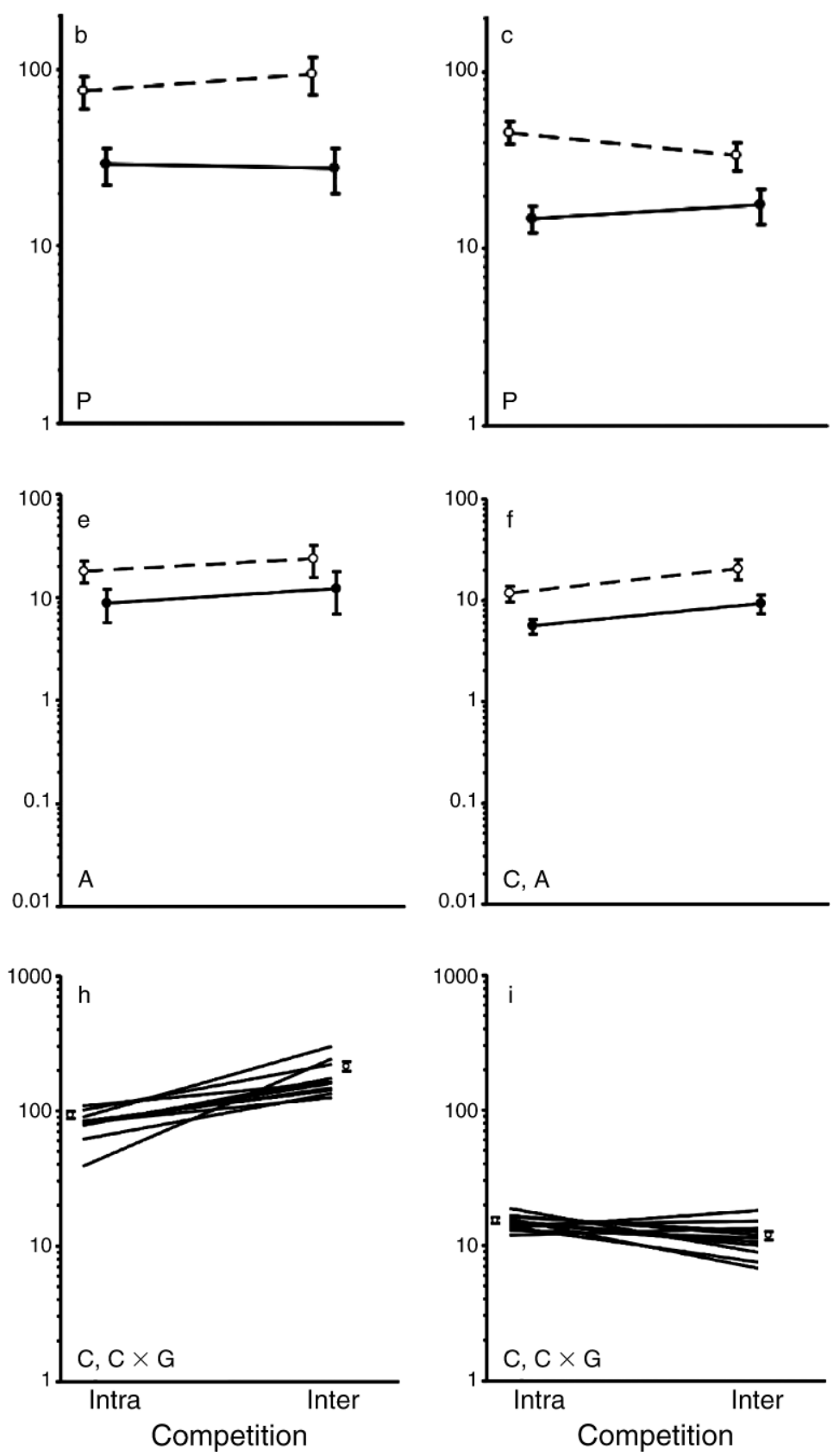
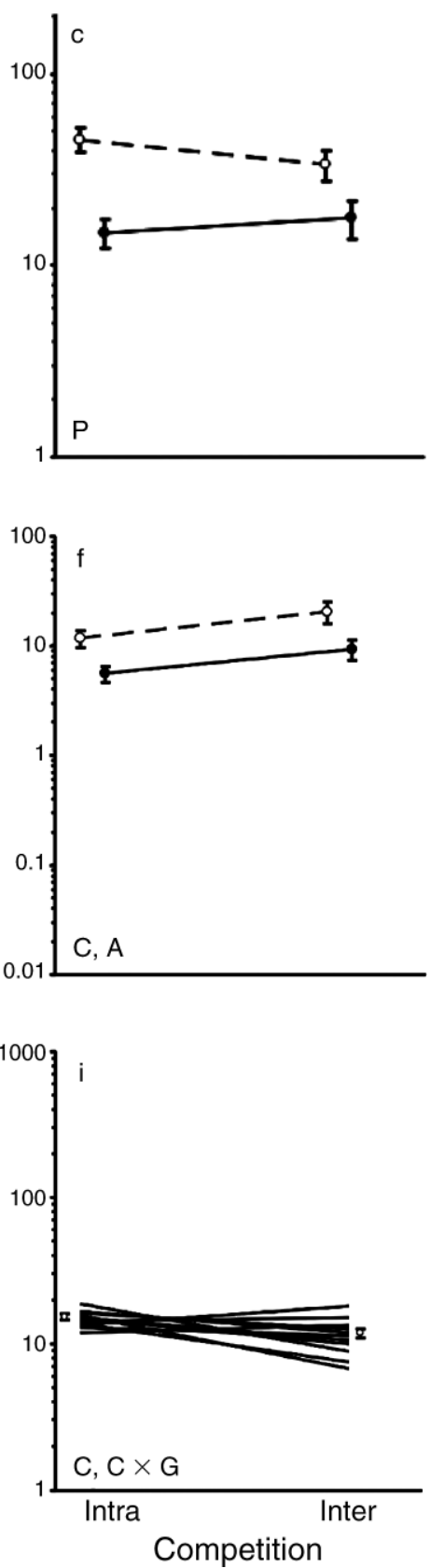

FIG. 1. The effects of predation, ants, and plant genotype on intra- vs. interspecific competition for three aphid specialists on Asclepias syriaca. This figure summarizes the results of factorial experiments manipulating each of three factors with competition; the ecological factors are organized in rows, and the aphid species in columns. In all graphs, the $y$-axis is a measure of population growth rate on a log scale: the number of aphids per capita, per plant (mean \pm SE) is shown for intraspecific competition on the left and interspecific competition on the right. In panels a-c, aphid performance is shown in the presence (solid lines) and absence (dashed lines) of predators. In panels $\mathrm{d}-\mathrm{f}$, aphid performance is shown in the presence (solid lines) and absence (dashed lines) of ants. The results of statistical tests are shown with single letters in the bottom-left corner. C, A, P, and G represent significant effects $(P<0.05)$ of competition, ants, predation, or milkweed genotype, respectively, and letters in parentheses indicate marginally 
families, one showed interspecific to be weaker than intraspecific competition, while the other showed the reverse (Fig. 1i; Appendix B). Finally, for A. nerii, eight families did not show significant differences between intra- and interspecific competition, while three families showed significant differences between the two types of competition with interspecific competition being significantly weaker than intraspecific in all cases (Fig. 1h; Appendix B).

\section{Discussion}

Our results indicate that multiple factors play important roles in structuring the community of milkweed aphids, and that these factors likely work together to promote the coexistence of these competing herbivores on a single plant resource. The relative strength of intra- and interspecific competition strongly depended upon ants, which were mutualists of Aphis asclepiadis, but antagonists of $A$. nerii and Myzocallis asclepiadis. Similarly, competition was variable among plant genotypes, suggesting a role for genetically variable host plants in the coexistence of these herbivores. Quite surprisingly, predation did not play a substantial role in promoting coexistence via a differential impact on the aphid species and their competitive interactions. Next we discuss these results in light of the importance of multitrophic interactions influencing species coexistence.

\section{Predator $\times$ competition}

Although predators had a strong negative effect on aphid populations, they did not confer a competitive advantage to any one species as the relative strength of intra- and interspecific competition were similar and did not depend on the presence of predators. We expected that $A$. nerii would suffer relatively less from predators than the other species based on its aposematic coloration, sequestered chemical defenses, and very high intrinsic rate of increase (Mooney et al. 2008). That predators did not affect competition is also unexpected given the "keystone" role predation has been shown to play in shaping diversity elsewhere by suppressing dominant competitors (Paine 1966, Chesson 2000).

It is important to note that predators may very well have reduced the strength of competition per se as our study only compared the relative strength of intra- and interspecific competition. In their seminal paper, Hairston et al. (1960) proposed that competition among herbivores would generally be weak because enemies would hold their abundance below the carrying capacity of shared plant resources. Predators reduced aphid abundance by $66 \%$ and thus almost surely reduced the
TABLE 2. Interactions of the ant Formica podzolica and aphids as the percentage time spent in three behaviors on plants with each of three aphid species.

\begin{tabular}{lrccc}
\hline \hline \multicolumn{1}{c}{ Species } & $\begin{array}{c}\text { Sample } \\
\text { size }\end{array}$ & Tending & Harvesting & Roaming \\
\hline A. asclepiadis & 9 & $86^{\mathrm{A}} \pm 29$ & $0^{\mathrm{A}}$ & $14^{\mathrm{A}} \pm 5$ \\
A. nerii & 10 & $70^{\mathrm{B}} \pm 22$ & $10^{\mathrm{B}} \pm 3$ & $20^{\mathrm{A}} \pm 6$ \\
M. asclepiadis & 7 & $0^{\mathrm{C}}$ & $82^{\mathrm{C}} \pm 31$ & $18^{\mathrm{A}} \pm 7$ \\
\hline
\end{tabular}

Notes: Within each behavior, superscript letters indicate the results of statistical tests for the effect of aphid species; ant behavior differed significantly $(P<0.05)$ where aphid species do not share a letter. Sample size is the number of ants observed (single ants on single plants); values are means \pm SE. Predation was not observed.

overall strength of competition. Nevertheless, our results demonstrate that a reduction in the strength of competition does not necessarily lead to a change in the outcome of competition among herbivores. Consequently, strong predator effects are not sufficient to guarantee a role of predators in maintaining herbivore coexistence and species diversity. A recent synthesis of theory underscores this result, with some models predicting that predation may have little impact on coexistence, even if prey populations decline in the presence of predators (Chase et al. 2002). The importance of antagonistic interactions in coexistence theory, especially in isolation of other ecological effects, may be overemphasized (Bruno et al. 2003).

\section{Ants $\times$ competition}

Ants can have strong effects on plant-arthropod communities through their impacts as mutualists and antagonists of herbivores (e.g., Wimp and Whitham 2001, Kaplan and Eubanks 2005, Mooney 2006). For example, Kaplan and Eubanks (2005) document how aphids attracted fire ants, which reorganize the arthropod communities in cotton agroecosystems, while Mooney (2006) found a similar dynamic in pine canopies. Our results also show that ants play an important role in shaping the composition of the milkweed aphid community. The net effect of ants was to promote the coexistence of $A$. asclepiadis with the other two more abundant and competitive species. Ants did not increase the abundance of $A$. asclepiadis in the absence of competition, suggesting that although they reduced predator abundance by three-fourths, this effect provided little benefit. Nevertheless, in the presence of competition, ants significantly increased $A$. asclepiadis abundance while, at the same time, decreasing the abundance of $A$. nerii and $M$. asclepiadis. Aphis asclepiadis thus suffered heavily from interspecific competition and ants benefited the aphid not, as is

significant effects $(0.05<P<0.10)$. Note that the vertical difference between lines represents the effects of predators, ants, and plant genotype, respectively, while the slope of the lines represents the degree of the difference between intra- and interspecific competition. In the plant genotype experiment (panels $\mathrm{g}-\mathrm{i}$ ), each line represents aphid performance on one of the 11 genetic families. For clarity the variance is not shown for each individual family; overall means $( \pm \mathrm{SE})$ are shown adjacent to the 11 genetic family lines. Significant single-letter factors are indicated as in panels a-f. 
usually envisioned, by providing protection from predators, but rather by ameliorating the negative effects of competition. This is a novel mechanism of the mutualistic benefits of ants to aphids. Although several studies have shown aphids indirectly suppress co-occurring herbivores (and potential competitors) via tending ants, these studies have not explicitly studied the effects of ants on competition among tended and untended herbivores (Styrsky and Eubanks 2007).

The results of behavioral observations supported our conclusion that $F$. podzolica is only a mutualist with $A$. asclepiadis and an antagonist of the other two aphids. When on plants with $A$. asclepiadis, ants spent the majority of their time tending (86\%), but significantly less than when they were on plants with $A$. nerii and $M$. asclepiadis (70\% and $0 \%$, respectively). The fact that ants had a negative effect on $A$. nerii, even while tending them and reducing predator abundance, demonstrates the complexity of such dynamics, as well as the importance of experimentally documenting the net effects of what may superficially appear to be positive interactions. The mechanism by which ants reduced populations of $A$. nerii and $M$. asclepiadis is unclear, but we did not observe any predation events in hundreds of person hours of observation (in this and other studies). Ant attendance carries costs for some aphids (Stadler and Dixon 1998); for $A$. nerii, these costs may exceed the benefits of tending because this aphid is more chemically defended and less palatable to predators than A. asclepiadis (Mooney et al. 2008). While ants did not prey upon $M$. asclepiadis, one possible explanation is that ants induced dispersion of this constitutively winged aphid.

Even in the presence of mutualist ants, the negative effects of interspecific competition were still stronger than those of intraspecific competition for A. asclepiadis. Consequently, ecological factors other than ants likely influence the success of $A$. asclepiadis and its coexistence with the other two species. Another experiment conducted at the same field site in the preceding year showed that plant genotype affects both the direction and the magnitude of the effects of ants on A. asclepiadis (Mooney and Agrawal, in press). Effects of plant genotype on aphid-ant interactions, and consequently on herbivore community structure, have also been reported for insects on hybrid poplars (Wimp and Whitham 2001). The results from our past work (Mooney and Agrawal, in press), in combination with those of the ants $\times$ competition experiment and the plant genotype $\times$ competition experiment (discussed in the next section), suggest that the success of $A$. asclepiadis may depend on a combination of host plant genotype as well as the presence of ants.

This set of results underscores a new direction in ecology, which considers the role of mutualism or positive interactions in species coexistence (Bronstein et al. 2003, Brunno et al. 2003, Schmitt and Holbrook 2003). Much of the work in this arena has focused on coexistence of plant species, and the role that microbes can play in facilitative coexistence. For example, both theory and some data indicate that the presence of mutualist mycorrhizal fungi in soil can enable the coexistence of plant species by altering abundances and competitive outcomes (Klironomos 2002, Bever 2003, Umbanhowar and McCann 2005). More generally, our work and that of others is beginning to highlight the dual role of organisms as antagonists and mutualists in a community context (Bronstein et al. 2003, Thomson 2003, Mooney 2007).

\section{Plant genotype $\times$ competition}

Because plant genotypes vary in resistance to multiple herbivores, it has long been speculated that plant genotypic differences structure herbivore communities (Karban 1989, Maddox and Root 1990, Roche and Fritz 1997, Wimp and Whitham 2001, Johnson and Agrawal 2007). However, the specific role of plant genotype in mediating competitive interactions between species is not well studied, especially outside the context of induced plant resistance (reviewed by McGuire and Johnson 2006). In our experiments, the interaction between plant genotype and competition was significant for all species, showing that plant genotype mediated the strength of competition. Although A. nerii was overall the competitively dominant aphid in this experiment, tests for the difference between intra- and interspecific competition on individual plant genetic lines showed that there were at least some lines on which coexistence was predicted for each aphid species. On one of the 11 genotypes studied, A. asclepiadis was predicted to coexist with the other two aphid species even though these experiments were conducted in the absence of mutualist ants (Fig. 1g; Appendix B). Similarly, for Myzocallis there appeared to be four genotypes on which coexistence with $A$. nerii would be expected. That plant genotype had a detectable effect at all in a laboratory setting has promising implications for its importance in the field, as differences between milkweed genotypes tend to be more pronounced in the latter case (Van Zandt and Agrawal 2004, Agrawal 2005; A. A. Agrawal, unpublished data). As discussed previously, dynamics between plant genotype and ecological factors such as mutualism and competition represent a novel mechanism for resource quality to affect arthropod community structure (Wimp and Whitham 2001, Johnson and Agrawal 2007, Johnson and Stinchcombe 2007).

\section{Synthesis}

The importance of competition and other ecological factors, such as predation, ants, and plant genotype, depends on how these species are spatially distributed in the field. For example, ants are remarkably patchy at local field sites, with some old fields harboring milkweed but relatively lacking in aphid-tending ants such as $F$. podzolica. Milkweed populations are consistently genetically diverse; in various experiments, including this one, genetic families from within a population vary up to 
fourfold in ecologically important traits (Agrawal 2004, 2005). Thus, the dual role of ants as antagonists (of $A$. nerii and $M$. asclepiadis) and mutualists (of $A$. asclepiadis) is likely to be spatially variable, while the role of heritable genetic variation is likely to be consistent. In other work, we have shown an interaction between heritable plant variation and effects of ants on two of the aphids studied here (Mooney and Agrawal, in press). We speculate that this same ant-plant interaction may be critical for the coexistence of aphid species on milkweeds.

One unstudied factor that is likely important for the coexistence of these aphids is phenology. Myzocallis asclepiadis colonizes plants first in the early spring, followed closely by $A$. asclepiadis. In the northeast USA, $A$. nerii colonizes last, as it moves up from the southern areas where it overwinters; in Ithaca, we typically do not see $A$. nerii in the field until mid- to late July, around the time our field experiments were conducted (Mooney et al. 2008). The competitive dominance of $A$. nerii may fit the classic competition-colonization trade-off (Levins and Culver 1971) from the perspective of the very late colonization of $A$. nerii. In addition, it is clear that $M$. asclepiadis is the most dispersive of the three species (R. A. Smith, K. A. Mooney, and A. A. Agrawal, personal observations). Thus, co-occurrence, and hence the importance of interspecific competition, is likely strongest at the end of the season. Whether the late arrival of $A$. nerii has implications for coexistence of $A$. asclepiadis and $M$. asclepiadis with this competitively dominant aphid remains to be tested.

In conclusion, our results are consistent with past experiments (e.g., Karban 1989), that find that no single factor can be used to predict the organization of insect herbivores on plants. Nonetheless, there are astonishingly few studies that have simultaneously examined the impacts of multiple factors on the strength of competition, especially in an experimental context. We have discovered some of the major factors that, in combination, contribute to the coexistence of aphid species on milkweed. Although $A$. nerii has the highest fecundity and is competitively dominant, ants mutualistically promote populations of $A$. asclepiadis by suppressing the other species. Variable plant genotypes also play a role in the success of both $A$. asclepiadis and $M$. asclepiadis, as coexistence with $A$. nerii is predicted on some but not all plant genetic families. Surprisingly, predation did not appear to play a role in promoting coexistence. Thus, our key result is that multiple ecological factors, though not predation, are responsible for promoting the coexistence of aphid species.

\section{ACKNOWLEDGMENTS}

We thank Kelly Goodsell for valuable assistance in both field experiments, Laura Kroon for help with the laboratory experiment, and Marc Johnson for donating the aluminum rings to exclude ants. Ian Kaplan, John Parker, and Sergio Rasmann, and two anonymous reviewers provided helpful comments on the manuscript. Our work is supported by the Cornell Presidential Research Scholars program, NSF-DEB 0447550, University of California at Irvine School of Biological
Sciences, and the Biogeochemistry and Biocomplexity Initiative at Cornell University.

\section{Literature Cited}

Addicot, J. F. 1978. Niche relationships among species of aphids feeding on fireweed. Canadian Journal of Zoology 56: 1837-1841.

Agrawal, A. A. 2004. Resistance and susceptibility of milkweed: competition, root herbivory, and plant genetic variation. Ecology 85:2118-2133.

Agrawal, A. A. 2005. Natural selection on common milkweed (Asclepias syriaca) by a community of specialized insect herbivores. Evolutionary Ecology Research 7:651-667.

Agrawal, A. A., and S. B. Malcolm. 2002. Once upon a milkweed. Natural History 111:48-53.

Allison, P. D. and SAS Institute. 1999. Logistic regression using the SAS system: theoryand application. SAS Institute, Cary, North Carolina, USA.

Bever, J. D. 2003. Soil community feedback and the coexistence of competitors: conceptual frameworks and empirical tests. New Phytologist 157:465-473.

Bonsall, M. B., J. C. Bull, N. J. Pickup, and M. P. Hassell. 2005. Indirect effects and spatial scaling affect the persistence of multispecies metapopulations. Proceedings of the Royal Society B 272:1465-1471.

Booth, R. E., and J. P. Grime. 2003. Effects of genetic impoverishment on plant community diversity. Journal of Ecology 91:721-730.

Bronstein, J. L. 1994. Our current understanding of mutualism. Quarterly Review of Biology 69:31-51.

Bronstein, J. L., W. G. Wilson, and W. E. Morris. 2003. Ecological dynamics of mutualist/antagonist communities. American Naturalist 162:S24-S39.

Bruno, J. F., J. J. Stachowicz, and M. D. Bertness. 2003. Inclusion of facilitation into ecological theory. Trends in Ecology and Evolution 18:119-125.

Chase, J. M., P. A. Abrams, J. P. Grover, S. Diehl, P. Chesson, R. D. Holt, S. A. Richards, R. M. Nisbet, and T. J. Case. 2002. The interaction between predation and competition: a review and synthesis. Ecology Letters 5:302-315.

Chase, J. M., W. G. Wilson, and S. A. Richards. 2001. Foraging trade-offs and resource patchiness: theory and experiments with a freshwater snail community. Ecology Letters 4:304-312.

Chesson, P. 2000. Mechanisms of maintenance of species diversity. Annual Review of Ecology and Systematics 31: 343-366.

Denno, R. F., M. S. McClure, and J. R. Ott. 1995. Interspecific interaction in phytophagous insects - competition reexamined and resurrected. Annual Review of Entomology 81:297-331.

Duffy, J. E., B. J. Carinale, K. E. France, P. B. McIntyre, E. Thebault, and M. Loreau. 2007. The functional role of biodiversity in ecosystems: incorporating trophic complexity. Ecology Letters 10:522-538.

Edson, J. L. 1985. The influences of predation and resource subdivision on the coexistence of goldenrod aphids. Ecology 66:1736-1743.

Farnsworth, K. D., S. Focardi, and J. A. Beecham. 2002. Grassland-herbivore interactions: How do grazers coexist? American Naturalist 159:24-39.

Gold, J. J., and J. S. Shore. 1995. Multiple paternity in Asclepias syriaca using a paired-fruit analysis. Canadian Journal of Botany 73:1212-1216.

Gurevitch, J., J. A. Morrison, and L. V. Hedges. 2000. The interaction between competition and predation: a meta-analysis of field experiments. American Naturalist 155:435-453.

Hairston, N. G., F. E. Smith, and L. B. Slobodkin. 1960. Community structure, population control, and competition. American Naturalist 94:421-425. 
Halaj, J., and D. H. Wise. 2001. Terrestrial trophic cascades: How much do they trickle? American Naturalist 157:262-281.

Harrison, S., C. D. Thomas, and T. M. Lewinsohn. 1995. Testing a metapopulation model of coexistence in the insect community on ragwort (Senecio jacobaea). American Naturalist 145:546-562.

Hubbell, S. P. 2001. The unified neutral theory of biodiversity and biogeography. Princeton University Press, Princeton, New Jersey, USA.

Hunter, M. D., and P. W. Price. 1992. Playing chutes and ladders: heterogeneity and the relative roles of bottom-up and top-down forces in natural communities. Ecology 73: 724-732.

Hutchinson, G. E. 1978. An introduction to population ecology. Yale University Press, New Haven, Connecticut, USA.

Johnson, M. T. J., and A. A. Agrawal. 2005. Plant genotype and environment interact to shape a diverse arthropod community on evening primrose (Oenothera biennis). Ecology $86: 874-885$.

Johnson, M. T. J., and A. A. Agrawal. 2007. Covariation and composition of arthropod species across plant genotypes of evening primrose (Oenothera biennis). Oikos 116:941-956.

Johnson, M. T. J., and J. R. Stinchcombe. 2007. An emerging synthesis between community ecology and evolutionary biology. Trends in Ecology and Evolution 22:250-257.

Kaplan, I., and R. F. Denno. 2007. Interspecific interactions in phytophagous insects revisited: a quantitative assessment of competition theory. Ecology Letters 10:977-994.

Kaplan, I., and M. D. Eubanks. 2005. Aphids alter the community-wide impact of fire ants. Ecology 86:1640-1649.

Karban, R. 1989. Community organization of Erigeron glaucus folivores: effects of competition, predation, and host plant. Ecology 70:1028-1039.

Klironomos, J. N. 2002. Feedback with soil biota contributes to plant rarity and invasiveness in communities. Nature 417:6770.

Kohler, S. L. 1992. Competition and the structure of a benthic stream community. Ecological Monographs 62:165-188.

Lawton, J. H., and D. R. Strong, Jr. 1981. Community patterns and competition infolivorous insects. American Naturalist 118:317-338.

Levins, R., and D. Culver. 1971. Regional coexistence of species and competition between rare species. Proceedings of the National Academy of Sciences (USA) 68:1246-1248.

Littell, R. C. 2006. SAS for mixed models. Second edition. SAS Institute, Cary, North Carolina, USA.

Maddox, G. D., and R. B. Root. 1990. Structure of the encounter between goldenrod (Solidago altissima) and its diverse insect fauna. Ecology 71:2115-2124.

McClure, M. S., and P. W. Price. 1975. Competition among sympatric Erythroneura leafhoppers (Homoptera: Cicadellidae) on American sycamore. Ecology 56:1388-1397.

McGuire, R. J., and M. T. J. Johnson. 2006. Plant genotype and induced responses affect resistance to herbivores on evening primrose (Oenothera biennis). Ecological Entomology $31: 20-31$.

Mooney, K. A. 2006. The disruption of an ant-aphid mutualism increases the effects of birds on pine herbivores. Ecology 87:1805-1815.
Mooney, K. A. 2007. Tritrophic effects of birds and ants on a canopy food web, tree growth, and phytochemistry. Ecology 88:2005-2014.

Mooney, K. A., and A. A. Agrawal. In press. Plant genotype shapes ant-aphid interactions: implications for community structure and indirect plant defense. American Naturalist.

Mooney, K. A., P. Jones, and A. A. Agrawal. 2008. Coexisting congeners: demography, competition, and interactions with cardenolides for two milkweed-feeding aphids. Oikos 117: 450-458.

Paine, R. T. 1966. Food web complexity and species diversity. American Naturalist 100:65-75.

Rathcke, B. J. 1976. Competition and coexistence within a guild of herbivorous insects. Ecology 57:76-87.

Ricklefs, R. E., and G. L. Miller. 2000. Ecology. Fourth edition. W. H. Freeman, New York, New York, USA.

Roche, B. M., and R. S. Fritz. 1997. Genetics of resistance of Salix sericea to a diverse community of herbivores. Evolution 51:1490-1498.

SAS Institute. 2003. SAS version 9.1. SAS Institute, Cary, North Carolina, USA.

Schmitt, R. J., and S. J. Holbrook. 2003. Mutualism can mediate competition and promote coexistence. Ecology Letters 6:898-902.

Schoener, T. W. 1983. Field experiments on interspecific competition. American Naturalist 122:240-285.

Stadler, B., and A. F. G. Dixon. 1998. Costs of ant attendance for aphids. Journal of Animal Ecology 67:454-459.

Strong, D. R. 1982. Harmonious coexistence of hispine beetles on Heliconia in experimental and natural communities. Ecology 63:1039-1049.

Strong, D. R., J. H. Lawton, and T. R. E. Southwood. 1984. Insects on plants. Harvard University Press, Cambridge, Massachusetts, USA.

Styrsky, J. D., and M. D. Eubanks. 2007. Ecological consequences of interactions between ants and honeydewproducing insects. Proceedings of the Royal Society B 274: $151-164$.

Thomson, J. 2003. When is it mutualism? American Naturalist 162:S1-S9.

Tilman, D. 1982. Resource competition and community structure. Princeton University Press, Princeton, New Jersey, USA.

Umbanhowar, J., and K. McCann. 2005. Simple rules for the coexistence and competitive dominance of plants mediated by mycorrhizal fungi. Ecology Letters 8:247-252.

Valone, T. J., and J. H. Brown. 1995. Effects of competition, colonization, and extinction on rodent species diversity. Science 267:880-883.

Van Zandt, P. A., and A. A. Agrawal. 2004. Specificity of induced plant responses to specialist herbivores of the common milkweed, Asclepias syriaca. Oikos 104:401-409.

Whitham, T. G., W. P. Young, G. D. Martinsen, C. A. Gehring, J. A. Schweitzer, S. M. Shuster, G. M. Wimp, D. G. Fischer, J. K. Bailey, R. L. Lindroth, S. Woolbright, and C. R. Kuske. 2003. Community and ecosystem genetics: a consequence of the extended phenotype. Ecology 84:559-573.

Wimp, G. M., and T. G. Whitham. 2001. Biodiversity consequences of predation and host plant hybridization on an aphid-ant mutualism. Ecology 82:440-452.

\section{APPENDIX A}

Time course of treatment effects on aphids over the season in the field experiments (Ecological Archives E089-125-A1).

\section{APPENDIX B}

Tests for the effects of intraspecific vs. interspecific competition for each aphid species on each of 11 milkweed genetic families (Ecological Archives E089-125-A2). 


\section{Ecological Archives E089-125-A1}

R. A. Smith, K. A. Mooney, and A. A. Agrawal. 2008. Coexistence of three specialist aphids on the common milkweed Asclepias syriaca. Ecology 89:2187-2196.

Appendix A. A figure showing time course of treatment effects on aphids over the season in the field experiments. 
PREDATION-BY-COMPETITION

\section{Aphis asclepiadis}

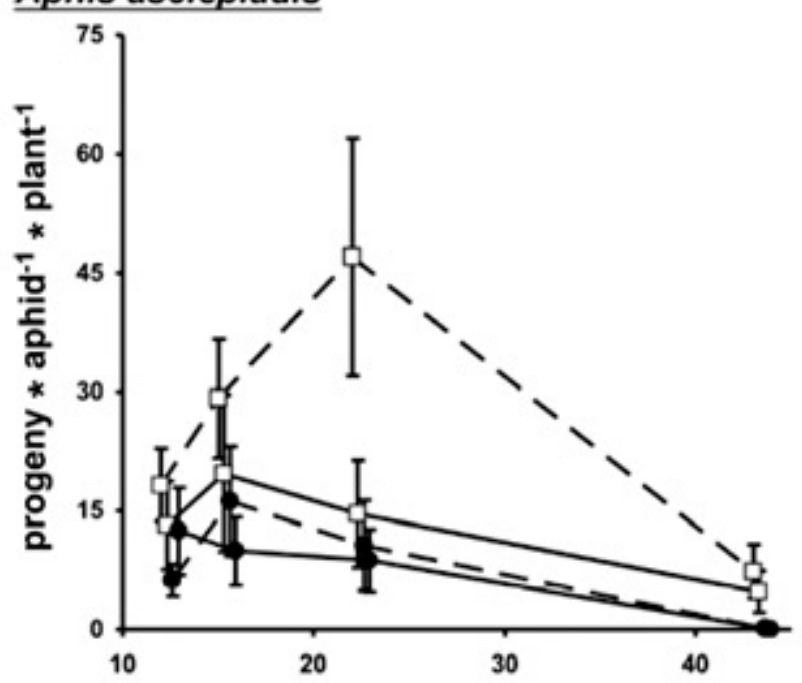

Aphis nerii

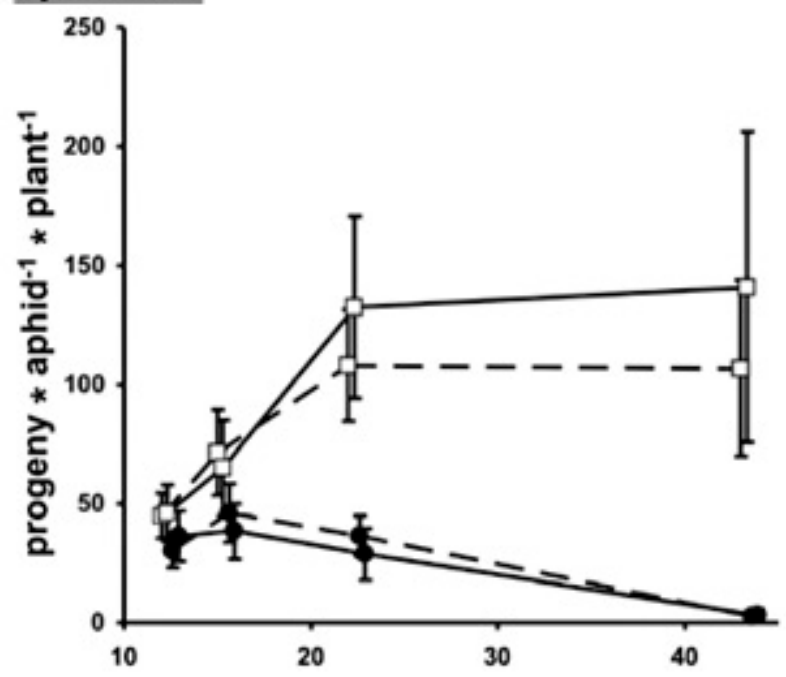

Myzocallis asclepiadis

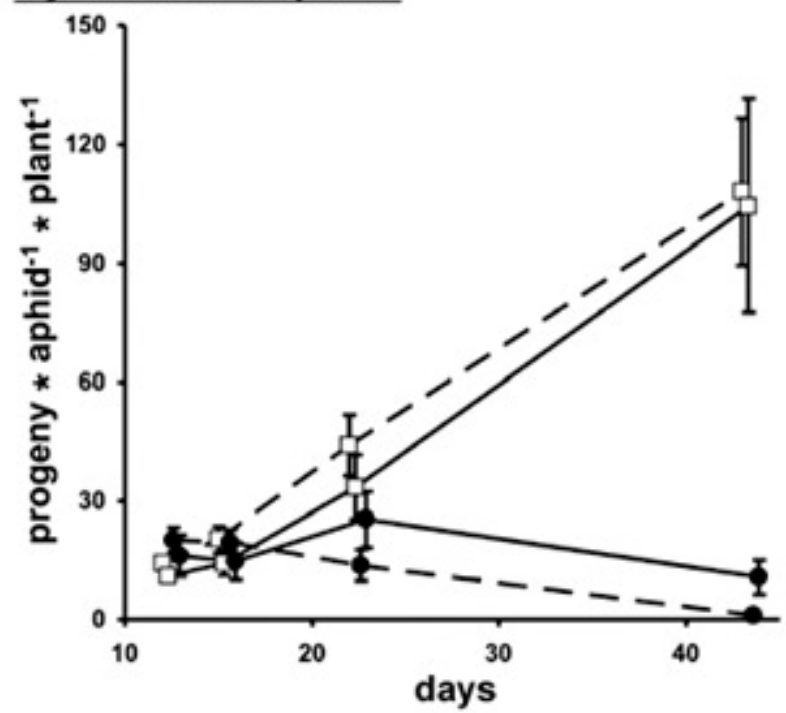

ANTS-BY-COMPETITION
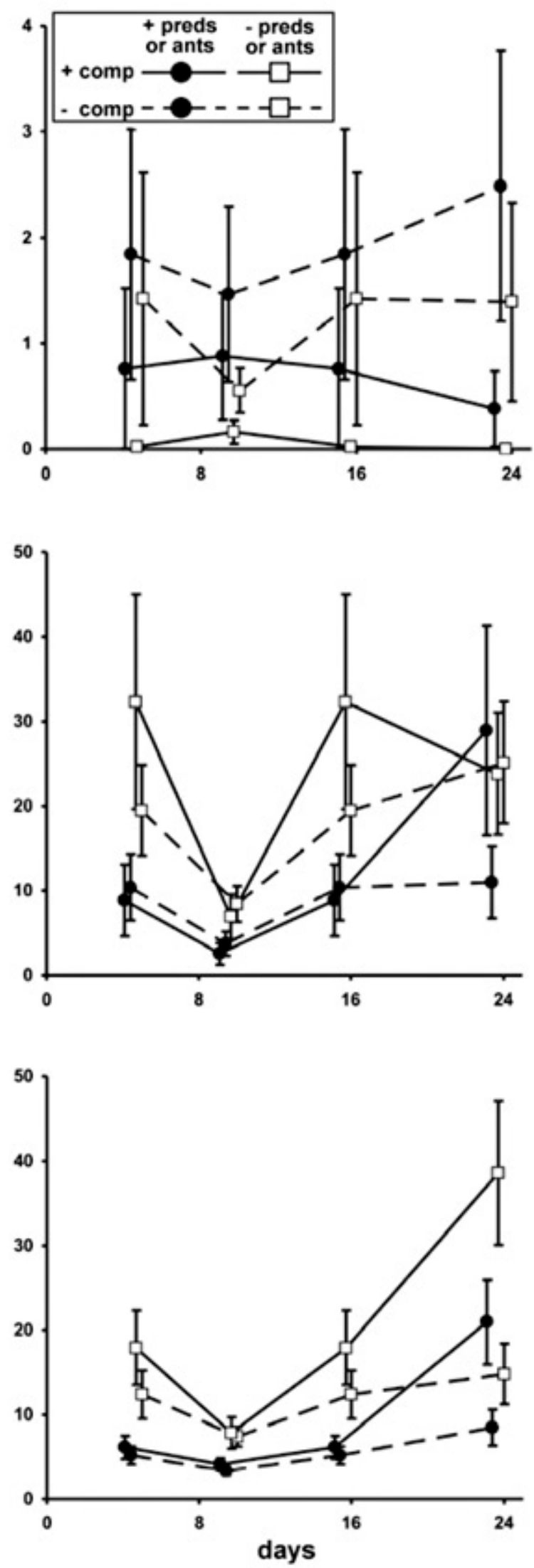
FIG. A1. Time course of treatment effects on aphids over the season in the field experiments. Mean (+- 1 SE) progeny produced per aphid per plant for Aphis asclepiadis (top row), Aphis nerii (middle row), and Myzocallis asclepiadis (bottom row) in predation-by-competition (left column) and ants-by-competition (right column) experiments with values shown for each sampling date. Predator or ant treatments (predationby-competition and ants-by-competition experiments, respectively) are shown with filled circles for presence and hollow squares for exclusion treatments. Treatments with and without competition are shown with solid and dashed lines respectively. 


\section{Ecological Archives E089-125-A2}

\section{R. A. Smith, K. A. Mooney, and A. A. Agrawal. 2008. Coexistence of three specialist aphids on the common milkweed Asclepias syriaca. Ecology 89:2187-2196.}

Appendix B (Table B1). Tests for the effects of intraspecific vs. interspecific competition for each aphid species on each of 11 milkweed genetic families.

\section{Species}
A. asclepiadis
M. asclepiadis
A. nerii

Family code Competition effect $\quad P \quad$ Competition effect $\quad P \quad$ Competition effect $\quad P$

\begin{tabular}{rrrrrrc}
\hline 3 & - & 0.22 & + & 0.42 & + & 0.28 \\
$\mathbf{8}$ & - & $\mathbf{0 . 0 3}$ & - & 0.81 & + & $<\mathbf{0 . 0 1}$ \\
$\mathbf{1 2}$ & - & $\mathbf{0 . 0 4}$ & - & 0.17 & + & $\mathbf{0 . 0 2}$ \\
$\mathbf{1 5}$ & - & $\mathbf{0 . 0 2}$ & - & 0.09 & + & 0.22 \\
18 & - & 0.11 & - & 0.29 & + & 0.23 \\
$\mathbf{2 3}$ & - & $\mathbf{0 . 0 3}$ & - & 0.12 & + & 0.29 \\
24 & + & 0.75 & - & 0.16 & + & 0.12 \\
25 & - & 0.53 & + & 0.81 & + & 0.74 \\
$\mathbf{2 8}$ & - & $\mathbf{0 . 0 5}$ & + & $\mathbf{0 . 0 2}$ & + & 0.14 \\
$\mathbf{3 0}$ & - & $\mathbf{0 . 0 7}$ & + & 0.51 & + & 0.31 \\
$\mathbf{3 2}$ & - & $\mathbf{0 . 0 1}$ & - & 0.20 & + & $<\mathbf{0 . 0 1}$ \\
\hline
\end{tabular}

Notes: Competition Effect indicates the relative effect of interspecific competition as compared to intraspecific competition( + or -$). P$ values are based on an $F$ test with numerator and denominator degrees of freedom one and four respectively. Significant results are in bold. 